\title{
HYPERTROPHIC CARDIOMYOPATHY IN PREGNANCY
}

\author{
Colonel J. F. WEBB, M.C., M.D., M.R.C.P. (Ed.) \\ Consultant Physician \\ Cambridge Military Hospital, Aldershot
}

SUMMARY: This paper describes a young patient who developed acute congestive failure in the terminal stages of her pregnancy as a result of hypertrophic cardiomyopathy. She presented a difficult diagnostic problem and serves to demonstrate the wide spectrum of cardiomyopathy as a disease process.

\section{Introduction}

Cardiomyopathy is described as an acute, sub-acute or chronic disorder of the heart muscle of unknown or obscure aetiology, often associated with endocardial or pericardial involvement, but not due to occlusive coronary atherosclerosis (Goodwin, Gordon, Hollman and Bishop, 1961). In essence the term implies isolated non-coronary myocardial disease (Brigden, 1957). The classification now described approximates to that noted by Goodwin (1966). Cardiomyopathy may be primary in which the heart is affected primarily and secondary in which the heart condition is a feature of a more widespread illness. Some of the conditions associated with each of these types are shown in Table $I$.

Table I

Some causes of primary and secondary cardiomyopathy

\begin{tabular}{|c|c|}
\hline Primary & Secondary \\
\hline $\begin{array}{l}\text { Virus infection } \\
\text { Endomyocardial fibrosis } \\
\text { Tropical congestive cardiomegaly } \\
\text { Alcohol } \\
\text { Pregnancy and puerperium } \\
\text { Amyloid disease of the heart } \\
\text { Cryptogenic (cause unknown) }\end{array}$ & $\begin{array}{l}\text { Anaemia } \\
\text { Endocrine disease } \\
\text { Infestations and infections } \\
\text { Connective tissue disorders } \\
\text { Irradiation } \\
\text { And others }\end{array}$ \\
\hline
\end{tabular}

Cardiomyopathy may present in a variety of ways, sometimes related to the clinical features of the primary disease when such is present; but usually, and particularly in the cryptogenic group, takes one of the following three forms, between which there may be a degree of overlap.

Congestive Cardiomyopathy which is the most common and in which the prominent clinical features are cardiomegaly, gallop rhythm, raised venous pressure and atrioventricular valve incompetence.

Constrictive Cardiomyopathy which mimics constrictive pericarditis and which often occurs in relation to amyloid disease of the heart. Cardiomegaly is not so marked as in the congestive type. There is also raised venous pressure with distinct "a " and " $v$ " waves and marked " $x$ " and " $y$ " descents in the jugular pulse.

Hypertrophic Cardiomyopathy which may be further sub-divided into:-those with ventricular outflow obstruction and demonstrating evidence of ventricular hyper- 
trophy, usually left, with some features of aortic stenosis and, less commonly, those without ventricular outflow obstruction. This latter group of patients may give a history of fainting and the only clinical abnormality may be a systolic murmur noted in the course of a routine examination or when they present suddenly in acute congestive failure as did the patient now described.

\section{Mrs. H. aged 32}

\section{Case history}

Admitted to the Louise Margaret Maternity Hospital, Aldershot on 22nd February, 1968 in acute congestive failure one day prior to being delivered of her first baby at term. During the previous month she had complained of increasing breathlessness whilst doing her ante-natal exercises, of swelling of the ankles, and she had required four pillows to sleep. She had been diagnosed as suffering from mitral regurgitation when she was seen on account of attacks of dizziness, in 1963. There was no other significant past history of illness and none of rheumatic fever. The family history was significant in that the maternal grandmother and one aunt had died of heart trouble and two others have evidence of it. One uncle also has heart trouble.

Examination demonstrated a normal pulse, with a rate of 120 per minute. There was marked increase in jugular venous pressure and moderate ankle oedema; on auscultation, there was a loud pansystolic murmur at the cardiac apex and along the left parasternal border; a mid-diastolic murmur was not heard.

There was no other clinical abnormality. Blood pressure was 120/70. The blood picture, e.c.g. and heart size on chest X-ray were normal.

She responded to digoxin and diuretics but relapsed temporarily on the third day of the puerperium. She eventually made a satisfactory recovery and was discharged from hospital on the 15th March, 1968, fit and free of symptoms.

Investigation. In view of the significance of a primipara of this age going into unexplained heart failure in pregnancy, she was investigated in the Cardiology Unit of the Middlesex Hospital in October, 1968. She was quite fit at this time, and her exercise tolerance was normal.

The pulse was normal, rate 70 , but there was a prominent flicking " a" wave in the jugular venous pulse. The cardiac impulse was normal: On ausculation a late systolic murmur more marked on exercise, was clearly audible at the apex and less so at the left sternal border. The heart sounds were normal and a third heart sound was heard. Other systems were normal.

Blood picture, E.S.R., e.c.g. and heart size on chest X-ray were normal.

Cardiac catheterisation demonstrated normal right heart pressures and gradients, but in the left heart the pulmonary capillary venous pressure (P.C.V.) or wedge pressures although normal at rest became abnormal on effort rising sharply to a mean pressure of $17 \mathrm{~mm} \mathrm{Hg}$. There was no significant gradient across the left ventricular outflow tract nor across the mitral valve at rest or on effort; the left ventricle end diastolic pressure was normal at all times. The post-ectopic beats showed a small fall in pressure suggesting poor ventricular function (Table II). 
Table II

Left heart pressures $(\mathrm{mm} \mathrm{Hg}$ ) showing the sharp rise in the wedge pressure on exercise and, at a later reading, the fall in $L V$ pressure with the post-ectopic beat

\begin{tabular}{lr|c|c}
\hline & & $\begin{array}{c}\text { At rest } \\
\text { (rate 78/min) }\end{array}$ & $\begin{array}{c}\text { Exercise } \\
\text { (rate 138/min) }\end{array}$ \\
\hline Pulmonary capillary venous & $\mathrm{a}$ & 4 & 20 \\
pressure (wedge). & $\mathrm{x}$ & 0 & 19 \\
& $\mathrm{v}$ & 3 & 20 \\
& Mean & 1 & 12 \\
Left ventricle & 3 & 17 \\
Aorta & & $90 / 0,2$ & $100 / 0,10$ \\
Later left ventricle) & Post-ectopic & $85 / 50$ & \\
\hline
\end{tabular}

Angiography demonstrated a thick left ventricle wall with an abnormal contour on its inner surface caused by irregular hypertrophy of the muscle and confirmed mitral regurgitation. Figures 1(a) and (b) show the left ventricle in systole and the abnormal contour of the ventricle can be seen. In particular a small pocket or split can be seen as a projection at the apex of the ventricle.
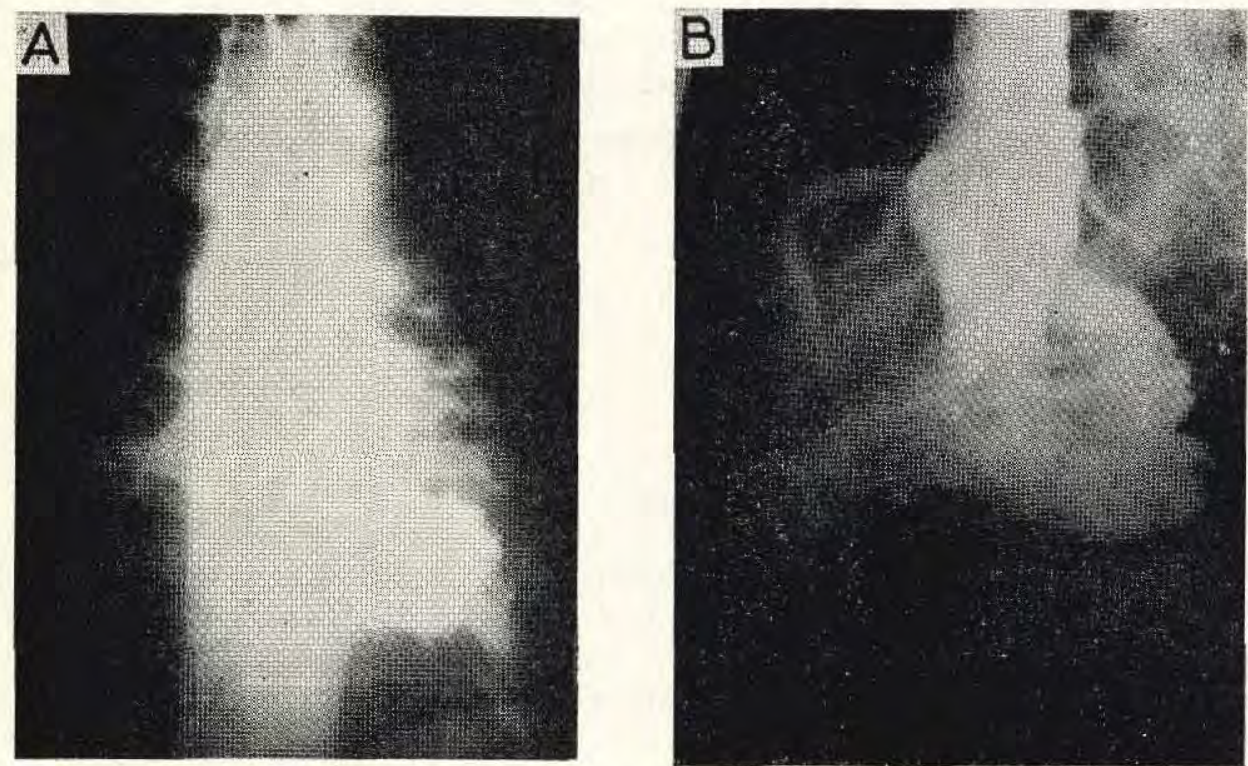

Fig. 1A, frontal and, B, lateral views of the left ventricular angiogram taken during systole, demonstrating the abnormal contour of the ventricular cavity with a slit or 'tail' at the apex.

(Table II and Figs 1A and B reproduced from Proc, roy. Soc. Med. Vol 63, January 1970)

\section{Discussion}

This patient demonstrated features of both congestive cardiomyopathy in the method of presentation, and of hypertrophic cardiomyopathy in the family history and the ventricle abnormality seen on angiography. 
Since she was delivered of her first baby at term within twenty-four hours of admission it may be that the onset of labour precipitated the failure, although this was not the view of the staff of the maternity unit who maintained that she went into labour after admission to hospital. The history does in fact suggest that she was gradually going into failure during the last month of her pregnancy. In the circumstances this would have been extremely difficult to diagnose, particularly as this is not the usual time of pregnancy for a patient suffering from heart disease to go into failure. Whatever the mechanics of the failure the cause was not immediately apparent.

Absence of obstruction to the ventricular outflow tracts and especially the left ventricle in cases of hypertrophic cardiomyopathy is uncommon, but this feature is described (Cohen et al, 1965, Goodwin, Gordon, Hollman and Bishop, 1961, Karatzas, Hamill and Sleight, 1968). A normal e.c.g., as in this patient, is however very unusual (Brigden, 1963), indeed when she was seen in 1963 some flattening of the $T$ waves in leads II III AVF and V6 was noted.

The mitral incompetence which occurs in a considerable number of patients with hypertrophic cardiomyopathy is due to malfunction of the valve resulting from the irregular hypertrophy of the muscle of the wall of the ventricle and the papillary muscles. This malfunction and hypertrophy probably explain the undue increase in the wedge pressure on exercise as noted in this patient. The prominent "a " wave in the jugular venous pulse might also be contributed to by the hypertrophied left ventricle bulging into the right ventricle--Bernheim effect.

Prophylactic antibiotic cover is indicated when dental attention and similar procedures are required by these patients, it may even be indicated in the puerperium, although obstetric opinion is divided on this point. When the diagnosis has been established prospective parents should be made aware of the risks before starting a pregnancy and in the event of the pregnancy being completed as in this patient, further pregnancies must be regarded as hazardous. Since these patients are more likely to develop thrombotic episodes (Brigden, 1957) oral contraceptives are contra-indicated.

Goodwin (1967) believes that there is a strong genetic influence in hypertrophic cardiomyopathy possibly involving some disturbance of endogenous catacholamine function within the heart, but whether such cases as the one described progress to obstruction of the ventricle outflow tracts is not known.

BRIGDEN, W. (1957). Lancet i, 1179.

\section{REFERENCES}

BRIGDEN, W. (1963). Practitioner 190, 222.

Cohen, J. EfFat, H., Goodwin, J. F., OAkley, C. M. and Steiner, R. E. (1964). Brit. Heart J. $26,16$.

Goodwin, J. F., Gordon, H., Hollman, A. and Bishop, M. B. (1961). Brit. med. J. i, 169.

Goodwin, J. F., (1964). Brit. med. J. i, 1527, 1595.

GoodwIN, J. F. (1966). in Symposium on "Disorders of the Heart and Circulation". Royal College of Physicians, Edinburgh.

GoodwIN, J. F. (1967). Brit. J. hosp. Med. II, 1000.

Karatzas, N. B., Hamill, J. and Sleight, P. (1968). Brit. Heart J. 30, 826. 